\title{
Ischaemic heart disease and prodromes of sudden cardiac death \\ Is it possible to identify high risk groups for sudden cardiac death?
}

\author{
JAN KYST MADSEN \\ From the Medical Department B, Frederiksborg County Hospital, Hillerod, Denomark
}

SUMMARY A study was carried out to determine the incidence of sudden cardiac death in a well defined population in relation to prodromes, medical history, and previous medical consultations before sudden cardiac death. In Frederiksborg county, Denmark (population 332 000), of 1309 consecutive deaths in a six month period, 166 were due to sudden cardiac death; among men aged $50-69,22 \%$ of all deaths were due to sudden cardiac death. The incidence per 1000 population per year by age group $(<50,50-69, \geqslant 70$ years) was $0.19,3.6,11.4$ in men and $0.12,1.0$, and 6.4 in women. The increasing incidence with age was significant. Ischaemic heart disease or hypertension had been recorded in $75 \%$ (124/166) of patients. Prodromes were reported in 54\% (38/71) of patients with angina, and in $26 \%$ (25/95) without. Nineteen per cent (32/166) had neither prodromes nor overt heart disease. Forty six per cent of patients with known ischaemic heart disease and $24 \%$ without had consulted a doctor less than four weeks before death. Eight per cent had had a myocardial infarction within a year of death.

Cardiac death is the leading cause of death in most countries in the industrialised world and accounts for $20-30 \%$ of all deaths. Approximately $60-70 \%^{1-3}$ of all cardiac deaths take place within 24 hours of the onset of acute symptoms and are often called sudden cardiac deaths. Sudden cardiac death is usually caused by ventricular arrhythmias with or without acute myocardial infarction. ${ }^{4}$

Sudden cardiac death is frequently the first manifestation of ischaemic heart disease. ${ }^{12}$ It may be preceded by acute myocardial infarction or angina pectoris. ${ }^{25}$ Furthermore, in patients admitted with suspected acute myocardial infarction, but in whom the diagnosis was ruled out, an increased risk of sudden death has been reported. ${ }^{67}$

Several attempts have been made to lower the mortality from sudden cardiac death both by reducing risk

Requests for reprints to Dr Jan Kyst Madsen, Medical Department B, Rigshospitalet, University Hospital, DK 2100 Copenhagen $\emptyset$, Denmark.

Accepted for publication 15 January 1985 factors for ischaemic heart disease-for example, hypertension, hypercholesterolaemia, or smoking-in the general population, ${ }^{8}$ or in groups with increased risk factors, ${ }^{10}$ and also by giving beta blockers after acute myocardial infarction. ${ }^{5}$ Moreover; patients recuscitated in mobile coronary care units have been shown to have a good prognosis. ${ }^{1112}$

The purpose of this study was to determine the incidence of sudden cardiac death in relation to prodromes, previous clinical findings, and previous medical consultations in hospital and in general practice before sudden cardiac death.

\section{Patients and methods}

\section{DEFINITIONS}

In this study sudden death was defined as unexpected natural death occurring instantaneously or within 24 hours after the onset of acute symptoms or signs. ${ }^{13}$ The case was included if death was unwitnessed but likely to have fulfilled the above definition. Deaths among residents of nursing homes were not counted as sudden deaths. Sudden cardiac death was defined 
Table 1 Incidence of sudden cardiac death (SCD) in a six month period

\begin{tabular}{|c|c|c|c|c|c|}
\hline $\begin{array}{l}\text { Age group } \\
(y)\end{array}$ & Population of area & $\begin{array}{l}\text { Total No of deaths } \\
\text { in six months }\end{array}$ & $\begin{array}{l}\text { Total No of SCD } \\
\text { in six months }\end{array}$ & $\begin{array}{l}S C D \text { as } \% \text { of death } \\
\text { rate }(95 \% C I)\end{array}$ & $\begin{array}{l}\text { Incidence of } S C D \text { per } \\
\text { year per } 1000 \\
\text { poprilation }(95 \% C I)\end{array}$ \\
\hline $\begin{array}{l}\text { Men: } \\
25-49 \\
50-69 \\
\geqslant 70 \\
\text { Women: }\end{array}$ & $\begin{array}{r}64712 \\
28095 \\
9093\end{array}$ & $\begin{array}{r}67 \\
233 \\
382\end{array}$ & $\begin{array}{r}6 \\
50 \\
52\end{array}$ & $\begin{array}{c}9.0(3.4-18.5) \\
21.5(16 \cdot 8-26 \cdot 3) \\
13.6(10 \cdot 2-17 \cdot 0)\end{array}$ & $\begin{array}{c}0.19(0.18-0.20) \\
3.6(3.5-3.7) \\
11.4(11.2-11.6)\end{array}$ \\
\hline $\begin{array}{l}\text { Women: } \\
25-49 \\
50-69 \\
\geqslant 70\end{array}$ & $\begin{array}{l}63032 \\
28151 \\
12445\end{array}$ & $\begin{array}{r}41 \\
133 \\
418\end{array}$ & $\begin{array}{r}4 \\
14 \\
40\end{array}$ & $\begin{array}{c}9.8(2.7-23) \\
10.5(5.3-15.7) \\
9.6(3.6-15.6)\end{array}$ & $\begin{array}{l}0.12(0.11-0.13) \\
1.0(0.9-1 \cdot 1) \\
6.4(6.3-6.5)\end{array}$ \\
\hline
\end{tabular}

$\mathrm{CI}$, confidence interval.

as sudden death of which the cause was proved to be cardiac at necropsy or assumed to be cardiac because of clinical circumstances.

\section{STUDY POPULATION}

The basis for the study was all 218 cases of sudden death occurring between 1 May 1982 and 31 October 1982 in Frederiksborg County (population 332 000). A total of 1309 deaths had occurred during that period. Some of the cases were identified when reported to the coroner or following admission to any of the four regional hospitals. The remainder were identified from death certificates after careful checks with the doctor who had issued the death certificates. The diagnosis was based on necropsy findings in 118 cases and on death certificates in the remaining 100 .

Of the 218 sudden deaths, 51 were of non-cardiac origin: 12 were due to pulmonary embolism, 21 to cerebrovascular disease, five to ruptured aortic aneurysm, four to gastrointestinal bleeding, three to asthma attacks, two to pneumonia, one to pulmonary carcinoma, one to epileptic seizure, and two to undetermined causes. In one case the general practitioner could not be identified. Thus the study population consisted of 166 cases of sudden cardiac death.

\section{MEDICAL HISTORY}

Information about prodromes, duration of fatal attack, and medical history was obtained from the coroner, police reports, hospital records, and from the patient's general practitioner, who in each case was asked to answer a standard questionnaire. Prodromes were defined as new symptoms or an aggravation of existing symptoms during the 14 days before death. Chest pain, dyspnoea, palpitation, and dizziness were classified as prodromes of cardiac origin. Systemic hypertension and congestive heart failure were considered to be present if the patient had been treated for either of these conditions. Previous admissions to coronary care units were noted. If an acute myocardial infarction had not been diagnosed such an admission was termed a "non-acute myocardial infarction episode."

\section{STATISTICAL METHODS}

The statistical methods used were the $\chi^{2}$ test, Fisher's exact test, and a two sample $t$ test. A p value of $<0.05$ was considered to be significant.

\section{Results}

Of 166 cases of sudden cardiac death, 58 were women (median age 76 (range 29-94) years) and 108 men (median age 67 (range 36-95) years). One hundred and eight deaths occurred at home, 27 after admission to hospital, five at work, four in ambulances, three during sporting activities, and 19 elsewhere.

One hundred deaths took place within one hour, 34 between one and six hours, and 32 between seven and 24 hours after the onset of acute symptoms. Sudden cardiac death accounted for $12.7 \%$ ( $95 \%$ confidence intervals, $10.9-14.6 \%$ ) of all deaths. Sudden cardiac death was found more often in men $(15.0 \%)$ than in women $(9.7 \%)(p<0.001)$. In men it accounted for $22 \%$ of all deaths in the age group $50-59$, significantly more than in older and younger men $(p<0.01)$ (Table 1). In women it accounted for approximately the same proportion of all deaths regardles of age (NS) (Table 1). In the middle aged (50-69 years) significantly more deaths among men than among women were due to sudden cardiac death $(p<0.01)$; in the older and younger age groups the proportions were similar for men and women (NS). The incidence of sudden car-

Table 2 Incidence of prodromes in two weeks before sudden cardiac death in relation to manifest ischaemic heart disease (angina pectoris, previous acute myocardial infarction, or chronic heart failure)

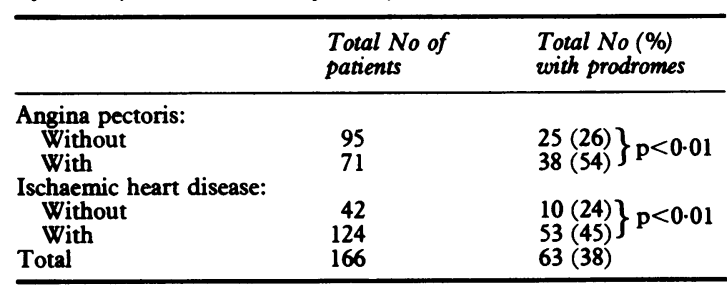




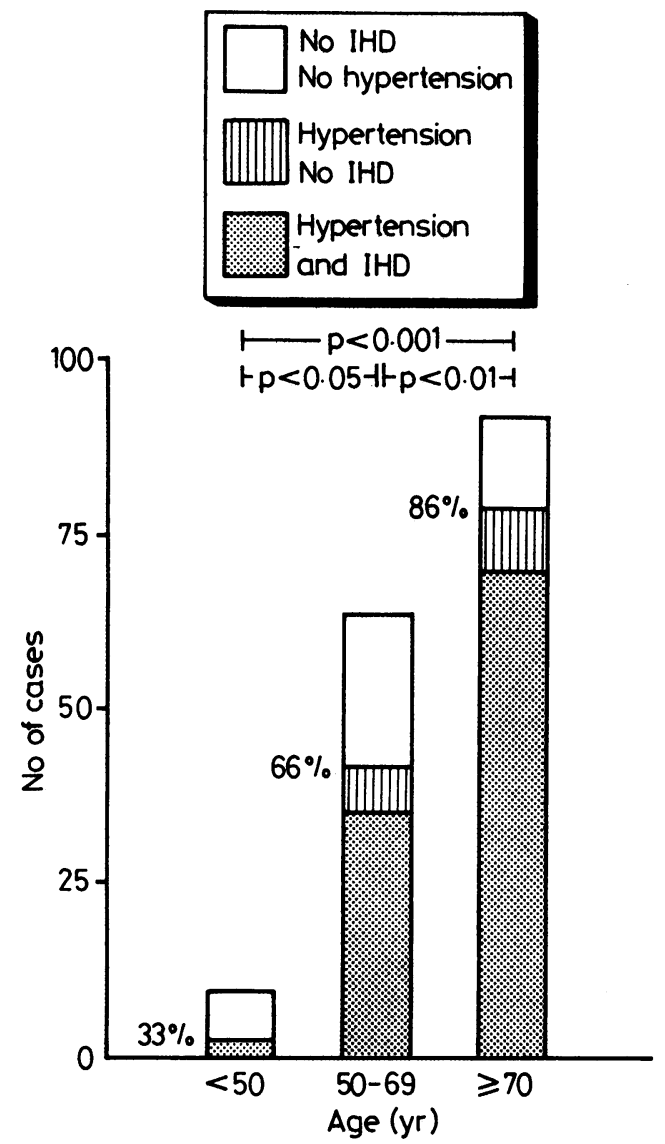

Fig. 1 Incidence of known ischaemic heart disease (IHD) with or without hypertension and presence of hypertension without IHD before sudden cardiac death in 166 cases by age group.

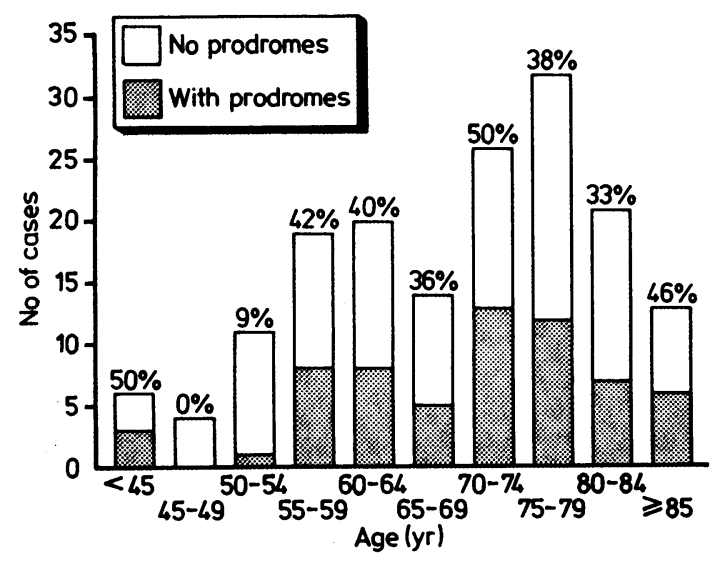

Fig. 2 Reported prodromes in the two weeks before sudden cardiac death in 166 cases in relation to age.

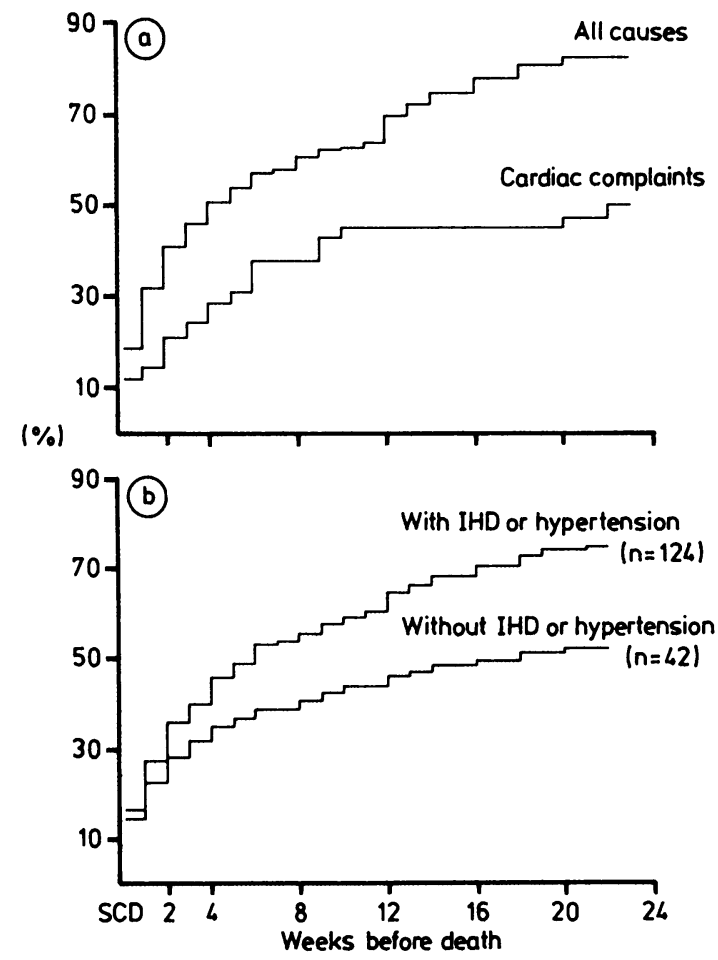

Fig. 3 Percentage of patients consulting a doctor in relation to time of sudden cardiac death in 166 cases; (a) shows all consultations and consultations for cardiac complaints alone and (b) all consultations for 124 patients with known ischaemic heart disease (IHD) (angina pectoris, previous acute myocardial infarction, or chronic hean failure) or hypertension or both and for 42 without.

diac death increased with age both for men and women $(p<0.001)$. For middle aged and older men the incidence was significantly higher than for women $(\mathrm{p}<0.01$ ) (Table 1).

ISCHAEMIC HEART DISEASE AND HYPERTENSION A history of ischaemic heart disease or hypertension was recorded in 124 cases ( 44 women, 80 men) and was more common in the older age group (Table 2, Fig. 1). Thirty eight patients had angina pectoris, 30 congestive heart failure, 90 previous acute myocardial infarction, and 20 hypertension.

\section{PRODROMES TO SUDDEN CARDIAC DEATH}

Patients with ischaemic heart disease had prodromes more often than those without ischaemic heart disease (Table 2$)(p<0.05)$. This was due to a high prevalence of prodromes in patients with angina pectoris. When patients with angina pectoris are excluded there was no significant difference in the incidence of prodromes in patients with $(36 \%)$ or without $(23 \%)$ 


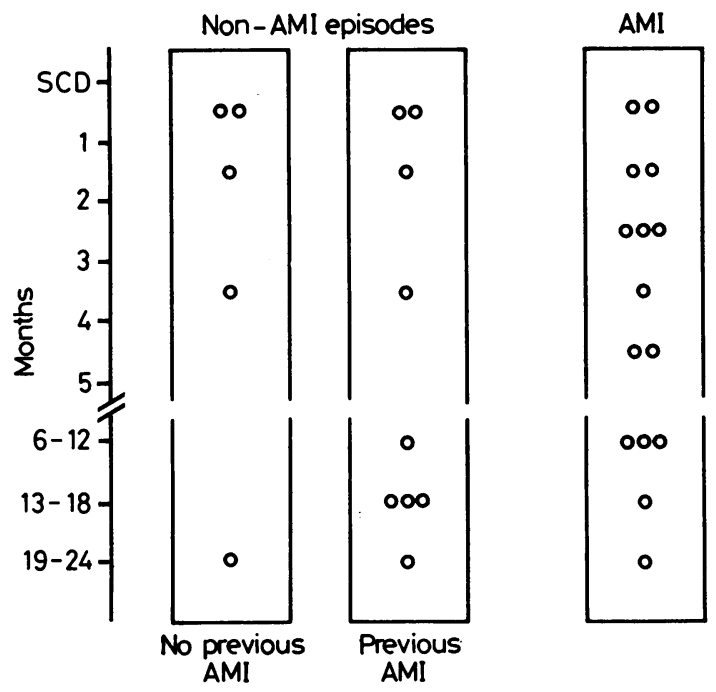

Fig. 4 Occurrence of acute myocardial infarction and non-acute myocardial infarction episodes in the two years before sudden cardiac death (SCD) in 166 cases. Non-acute myocardial infarction episodes (admissions with suspicion of acute myocardial infarction but not confirmed) are divided according to whether there was previous acute myocardial infarction.

ischaemic heart disease or hypertension or both (NS). The occurrence of prodromes was unrelated to age (Fig. 2) (NS).

\section{RECENT MEDICAL CONSULTATION}

Ninety six patients had seen a doctor within the two months before sudden cardiac death; 71 of these consultations were because of cardiac symptoms (Fig. 3a). Of the 124 patients with ischaemic heart disease or hypertension or both, $46 \%$ had seen a doctor within four weeks of death and, of the remaining 42 patients, $26 \%$ had seen a doctor during the same period $(\mathrm{p}<0.05)$ (Fig. 3b).

\section{ADMISSION TO CORONARY CARE UNIT}

Non-acute myocardial infarction episodes were

Table 3 Incidence of hypertension or angina pectoris or both in relation to chronic heart failure in victims of sudden death who had had an acute myocardial infarction less than one year before death. Figures in parentheses are numbers receiving beta blockers

\begin{tabular}{llll}
\hline & \multicolumn{3}{l}{ Chronic heart faihore } \\
\cline { 2 - 3 } & No & Yes & Total \\
\hline $\begin{array}{l}\text { Hypertension or angina } \\
\text { pectoris or both: }\end{array}$ & & & \\
No & 1 & 1 & 2 \\
Yes & $1(1)$ & $10(4)$ & $11(5)$ \\
Total & $2(1)$ & $11(4)$ & $13(5)$ \\
\hline
\end{tabular}

reported in 26 patients, 14 episodes occurring less than two years before death (Fig. 4), whereas acute myocardial infarction was diagnosed in 49 patients, 15 occurring less than two years before death (Fig. 4). Ten $(6.0 \%)$ of the 166 patients had been in a coronary care unit less than two months before death. In 13 (7.8\%) cases of sudden cardiac death acute myocardial infarction was recorded less than one year before death. Eleven had angina pectoris or hypertension, 10 of whom were treated for congestive heart failure and five received beta blockers (Table 3 ).

\section{Discussion}

Sudden cardiac death is an important cause of death in middle aged men, among whom almost a quarter of all deaths are due to sudden cardiac death. This accords with the established fact that death due to ischaemic heart disease is the main cause of death in this group.

The incidence of sudden cardiac death in this study (as given in Table 1) corresponds well with that in the study of Romo from Helsinki even though he included only cases of sudden death occurring within one hour of the onset of symptoms. ${ }^{14}$ In men he found an incidence of 0.1 to 1.7 per 1000 under 50 years, of 1.7 to 6.4 from 50-69 years, and of 13.1 to 19.5 over 69 years. For women the corresponding figures were 0.1 to $0.2,0.4$ to $2.0,1.5$ to $7 \cdot 1$. In the FraminghamAlbany study of men the incidence per 1000 was 1.2 , 3.9 , and 3.0 respectively in age groups $45-54,55-64$, and 65-74. ${ }^{15}$ This differs from Romo's findings and from our own as regards the oldest age group. The difference is difficult to explain, but in the Framingham-Albany study only 10 deaths in this age group were recorded.

One approach to prevention of sudden cardiac death may be to identify and treat subjects at greatest risk. In this study $75 \%$ of all patients who died of sudden cardiac death had manifest ischaemic heart disease or hypertension. A similar proportion was found in Baltimore ${ }^{3}$ but a lower one in other studies. ${ }^{116}$ In the present study ischaemic heart disease was not recorded in $70 \%$ of all patients with sudden cardiac death under 50 years of age and in $45 \%$ between 50 and 69 years of age (Fig. 1). Table 4 shows the estimated prevalence of ischaemic heart disease, defined as previous acute myocardial infarction or existing angina pectoris, in the Danish population. The estimate is based on other Danish population studies. ${ }^{17-19}$ On the basis of these figures is calculated the incidence of sudden cardiac death in subjects with and without ischaemic heart disease. Among younger subjects sudden cardiac death occurs mainly in those without known ischaemic heart disease, whereas in middle aged men an equal number occurs in men with 
Table 4 Estimated prevalence of ischaemic heart disease (IHD), defined as previous acute myocardial infarction or angina pectoris, in a Danish population ${ }^{17-19}$ and estimated incidence of sudden cardiac death (SCD) in subjects with and without ischaemic heart disease

\begin{tabular}{|c|c|c|c|c|}
\hline \multirow{3}{*}{$\underset{(y r)}{\text { Age group }}$} & \multirow{3}{*}{$\begin{array}{l}\text { Incidence of SCD } \\
\text { (per } 1000 \text { population) }\end{array}$} & \multicolumn{3}{|c|}{ Estimated values (rate per 1000 population) } \\
\hline & & \multirow{2}{*}{$\begin{array}{l}\text { Prevalence of } \\
I H D\end{array}$} & \multicolumn{2}{|c|}{ Incidence of SCD in subjects } \\
\hline & & & With IHD & Without IHD \\
\hline \multicolumn{5}{|l|}{ Men: } \\
\hline $\begin{array}{l}<50 \\
50-69 \\
\geqslant 70\end{array}$ & $\begin{array}{l}0.019 \\
0.36 \\
1.14\end{array}$ & $\begin{array}{r}1.3 \\
10.0 \\
13.0\end{array}$ & $\begin{array}{r}7.5 \\
19.3 \\
73.5\end{array}$ & $\begin{array}{l}0.095 \\
1.8 \\
2.3\end{array}$ \\
\hline \multicolumn{5}{|l|}{ Women: } \\
\hline $\begin{array}{l}<50 \\
50-69 \\
\geqslant 70\end{array}$ & $\begin{array}{l}0.012 \\
0.10 \\
0.64\end{array}$ & $\begin{array}{r}1.0 \\
2.0 \\
10.0\end{array}$ & $\begin{array}{l}\overline{28} \cdot 6 \\
45 \cdot 0\end{array}$ & $\begin{array}{l}0.13 \\
0.43 \\
2.4\end{array}$ \\
\hline
\end{tabular}

and without known ischaemic heart disease. In middle aged women and elderly men and women most sudden cardiac deaths occur in subjects with known ischaemic heart disease. Overall, most sudden cardiac deaths occur in subjects with known ischaemic heart disease. If effective prevention programmes were possible, the most immediate effect could be on the total number of sudden cardiac deaths in programmes applied to subjects with existing ischaemic heart disease.

The recorded incidence of prodromes before sudden cardiac death depends on the method of investigation. In our study $38 \%$ of cases were reported to have had prodromes, but this included only information available from doctors, police reports, etc-that is, only of prodromes so severe that they had been reported before death or that the relatives had disclosed after death. In constrast, Alonzo et al interviewed the relatives after death and found that $64 \%$ of victims had complained of prodromes. ${ }^{16}$ In our study, in $28 \%$ of all cases of sudden cardiac death the victims had consulted a doctor in the two weeks before death; this figure is slightly lower than in other studies, in which the proportion was $36-38 \% .^{31416}$

More of the patients with known ischaemic heart disease or hypertension had consulted a doctor recently, $32 \%$ within two weeks and $61 \%$ within two months (Fig. 3b), compared with $51 \%$ in the study of Alonzo et al . ${ }^{16}$ Prodromes were very frequent in this group especially among patients with angina pectoris. Of patients without ischaemic heart disease or hypertension, $14 \%$ had consulted a doctor in the two weeks before death (Fig. 3b), a similar proportion to that found by Alonzo et al. ${ }^{16}$ Twenty four patients had prodromes that retrospectively were found to be cardiac in origin, but no action had been taken because of them. Thirty two patients (19\% of all cases of sudden cardiac death) could not have been identified as being at risk for sudden cardiac death by detecting preexisting ischaemic heart disease or hypertension or by the presence of cardiac prodromes.
Non-acute myocardial infarction episodes are reported to be associated with an increased risk of cardiac death. ${ }^{67}$ In our study, in the 166 cases of sudden cardiac death, only 14 (8\%) patients had nonacute myocardial infarction episodes less than two years before death, which is a very small proportion (Fig. 4) but comparable to the figure of $15(9 \%)$ who had suffered from acute myocardial infarction over a similar period. Prophylaxis in this group may therefore be almost as important as in patients after acute myocardial infarction.

In only 13 patients had an acute myocardial infarction occurred less than one year before death, which is the period often recommended for medical prophylaxis after acute myocardial infarction (Fig. 4). Eleven of these 13 had angina pectoris or hypertension-possible indications for beta blocker treatment-and five were already receiving beta blockers (Table 3). At the time of the study none of the hospitals in the region gave beta blockers prophylactically to patients with acute myocardial infarction. Thus if acute myocardial infarction patients with hypertension or angina pectoris are treated with beta blockers or any other drug with a possible prophylactic effect on sudden cardiac death only very few cases of sudden cardiac death could possibly be prevented. Furthermore the impact of sudden cardiac death in society would hardly be influenced even by the use of routine prophylactic treatment after acute myocardial infarction since only $8 \%$ of sudden cardiac death victims had acute myocardial infarction less than one year before death.

Financial support was received from the Danish Heart Foundation, August Frederik Wedell Erichsens Legat, Arvid Nilssons Fond, and the Foundation for Medical Research of Bornholm, Frederiksborg, Roskilde, Storstrøm, and Vestsjaelland counties. 


\section{References}

1 Hinkle LE Jr. The immediate antecedents of sudden death. Acta Med Scand 1982; suppl 651: 207-17.

2 Armstrong A, Duncan B, Oliver MF, et al. Natural history of acute coronary heart attacks. A community study. Br Heart F 1972; 34: 67-80.

3 Kuller L, Cooper M, Perper J. Epidemiology of sudden death. Arch Intern Med 1972; 129: 714-9.

4 Liberthson RL, Nagel EL, Hirschman JC, Nussenfeld SR, Blackbourne BD, Davis JH. Pathophysiologic observations in prehospital ventricular fibrillation and sudden cardiac death. Circulation 1975; 49: 790-8.

5 The Norwegian Multicenter Study Group. Timololinduced reduction in mortality and reinfarction in patients surviving acute myocardial infarction. $N$ Engl F Med 1981; 304: 801-7.

6 Madsen JK, Hansen JF. The prognosis for patients admitted to a coronary care unit due to suspected acute myocardial infarction with and without confirmed diagnosis. Acta Med Scand 1982; 211: 453-7.

7 Schroeder JS, Lamb IH, Hu M. Do patients in whom myocardial infarction has been ruled out have a better prognosis after hospitalization than those surviving infarction? N Engl f Med 1980; 303: 1-5.

8 World Health Organisation European Collaborative Group. Multifactorial trial in the prevention of coronary heart disease: 3 . Incidence and mortality results. Eur Heart $\mathcal{F}$ 1983; 4: 141-7.

9 Hjermann I, Byre KV, Holme I, Leren P. Effect of diet and smoking on the incidence of coronary heart disease. Report from the Oslo Study Group of a randomised trial in healthy men. Lancet 1981; ii: 1303-10.
10 Multiple Risk Factor Intervention Trial Research Group. Multiple risk factor intervention trial. Risk factor changes and mortality results. fAMA 1982; 248: 146577.

11 Wennerblom B, Holmberg S, Wedel H. The effect of a mobile coronary care unit on mortality in patients with acute myocardial infarction or cardiac arrest outside hospital. Eur Heart f 1982; 3: 504-15.

12 Eisenberg MS, Hallstrom A, Bergner L. Long-term survival after out-of-hospital cardiac arrest. $N$ Engl $\mathcal{F}$ Med 1982; 306: 1340-3.

13 Paul O, Schatz M. On sudden death. Circulation 1971; 43: 7-10.

14 Romo M. Factors related to sudden death in acute ischaemic heart disease. Acta Med Scand 1972; 547 (suppl): 1-92.

15 Kannel WB, Doyle JT, McNamara PM, Quickenton P, Gordon T. Precursors of sudden coronary death. Factors related to the incidence of sudden death. Circulation 1975; 51: 606-13.

16 Alonzo AA, Simon AB, Feinleib M. Prodromata of myocardial infarction and sudden death. Circulation 1975; 52: 1056-62.

17 Jensen G. Epidemiology of chest pain and angina pectoris. With special reference to treatment needs. Acta Med Scand 1983; 682 (suppl): 1-120.

18 Agner E. Natural history of angina pectoris, possible previous myocardial infarction and intermittent claudication during the eighth decade. Acta Med Scand 1981; 210: 271-6.

19 Agner E, Damm P, Hansen PF, Schroll M. Causes of hospitalisation in different age intervals: from the Glostrup Population Studies. Dan Med Bull 1982; 29: 140-4. 